\title{
miR-2IO is a Serological Biomarker for Predicting Recurrence and Prognosis of Colon Carcinoma Patients with Liver Metastases After Radiofrequency Ablation Treatment
}

This article was published in the following Dove Press journal:

Cancer Management and Research

\author{
Yong Zhang' \\ Yu-Mei Zhou ${ }^{2}$ \\ Zu-Jian Zhang ${ }^{3}$ \\ Xin $\mathrm{Li}^{3}$ \\ 'Department of Radiology, People's \\ Hospital of Deyang City, Deyang City, \\ Sichuan Province 618000, People's \\ Republic of China; ${ }^{2}$ Outpatient \\ Department, People's Hospital of Deyang \\ City, Deyang City, Sichuan Province, \\ 618000, People's Republic of China; \\ ${ }^{3}$ Department of Interventional Radiology, \\ People's Hospital of Deyang City, Deyang \\ City, Sichuan Province 618000, People's \\ Republic of China
}

Purpose: Hepatic metastasis of colon carcinoma seriously affects the prognosis of patients, and miRNA has attracted much attention in predicting hepatic metastasis of colon carcinoma (CC). This research aimed to explore the predictive role of miR-210 in serum for recurrence and prognosis of CC patients with hepatic metastasis.

Methods: Altogether, 150 patients with liver metastases of $\mathrm{CC}$ (research group, RG) and 130 patients with non-metastatic of CC (control group, CG) admitted to People's Hospital of Deyang City from March 2012 to March 2015 were obtained and their serum was collected. miR-210 in the RG and the CG, and miR-210 in the RG after radiofrequency ablation treatment were detected, the relationship between miR-210 and pathological parameters of CC patients with hepatic metastasis was analyzed, and patients in the RG were followed up for 5 years to analyze the recurrence, overall survival (OS) and disease-free survival (DFS). The area under the curve (AUC) of receiver operating characteristic curve (ROC) was applied to test the predictive value of miR-210. Cox regression was applied to analyze the independent prognostic factors of patients.

Results: miR-210 in the RG was evidently higher than that in the CG, and AUC for distinguishing hepatic metastasis of CC was 0.907 . miR-210 had a close correlation with lymph node metastasis, distant metastasis and pathological differentiation. After treatment, miR-210 in the RG was evidently reduced, and the serum was higher in patients with recurrence and with poor prognosis. AUC for predicting recurrence was 0.858 , and AUC for predicting poor prognosis was 0.843 . High miR-210 was closely related to lower 5-year OS and DFS and is also an independent prognostic factor affecting patients' 5-year OS.

Conclusion: miR-210 is enhanced in hepatic metastasis of CC, which is a serological biomarker for predicting recurrence and prognosis of patients with hepatic metastasis of $\mathrm{CC}$ after radiofrequency ablation, and has great clinical application value.

Keywords: hepatic metastasis of colon carcinoma, miR-210, radiofrequency ablation, recurrence, prognosis

\section{Introduction}

Colon carcinoma, as a digestive tract tumor, is an important factor of carcinoma death in developed countries. ${ }^{1,2}$ Hepatic metastasis is the main reason for colon carcinoma death and has poor prognosis. The OS can be as low as $10 \%$ in 5 years. ${ }^{3}$ Radiofrequency ablation is a non-surgical minimally invasive treatment method for
Correspondence: Yong Zhang

Department of Radiology,

People's Hospital of Deyang City, No.

173, Section I, Taishan North Road,

Jingyang District, Deyang City, Sichuan

Province 618000, People's Republic of

China

Tel +86-I5883616210

Email Yongzhang210@hotmail.com
Cancer Management and Research 2020:12 9077-9085

9077 
colon carcinoma patients with hepatic metastasis, in which heat energy is deposited by high-frequency current pulses, thus destroying the tumor and hindering the disease process. ${ }^{4,5}$ Although the treatment mode is continuously optimized, the liver of colon carcinoma patients with hepatic metastasis is still in an immunosuppressive state, resulting in rapid disease progression and high recurrence rate (up to $86.1 \%$ ). ${ }^{6,7}$ Therefore, it is still of great value to investigate the effect of radiofrequency ablation on the recurrence and prognosis of colon carcinoma patients with hepatic metastasis.

microRNA (miRNA) is an organism's physiological and pathological regulator composed of 20-25 nucleotides, which has regulatory effects on cell cycle, migration, invasion and other cell processes, and also has certain influence on the survival and pathological changes of various tumors. ${ }^{8,9}$ In addition, miRNA, as a serological indicator, has certain clinical value for tumor diagnosis, prognosis and recurrence prediction. ${ }^{10,11}$ For example, miR-4772-3p in serum is helpful to predict tumor recurrence in patients with stage II/III colon carcinoma. miR629 is a potential biological indicator for diagnosis and prognosis of pancreatic carcinoma. ${ }^{11,12}$ In this study, we mainly focused on miR-210 in serum. Previous researches have shown that miR-210 is carcinogenic in colon carcinoma and can be applied for diagnosis and prognosis prediction. ${ }^{13}$ In addition, it is closely related to the chemoresistance and radiation sensitivity of 5-fluorouracil in colon carcinoma cells, and participates in the pathological regulation mechanism. ${ }^{14,15}$ It has been reported that miR210 has potential value in differentiating the differential expression between colon carcinoma and hepatic metastasis, but there are still few related reports. ${ }^{16}$

The research intended to analyze the predictive role of miR-210 in serum for recurrence and poor prognosis after radiofrequency ablation in hepatic metastasis of colon carcinoma, hoping to provide reference for the treatment and prevention of such patients.

\section{Materials and Methods \\ General Data}

Altogether 150 patients with liver metastases of colon carcinoma from March 2012 to March 2015 were selected as the research group (RG), including 79 men and 71 women with an average age of (62.02 \pm 15.37$)$ years. Another 130 patients with non-metastatic colon carcinoma were selected as the control group (CG), including 75 men and 55 women, with an average age of (61.56 \pm 13.87$)$ years. The study was approved by the Ethics Committee of Deyang people's Hospital and in accordance with the Helsinki Declaration. The participants and their guardians have signed the informed consent form.

\section{Inclusion and Exclusion Criteria}

Inclusion criteria: (1) The follow-up data were complete; (2) All patients have received radiofrequency ablation; (3) Patients were diagnosed as colon cancer by pathology, and there was liver metastasis; ${ }^{17}$ (4) Patients with no cognitive and communication barriers.

Exclusion criteria: (1) Patients with other malignant tumors or other severe diseases; (2) Colon cancer patients with distant metastasis except liver; (3) The estimated survival time was no more than 3 months; (4) Pregnant or lactating women; (5) Patients with infectious diseases or autoimmune diseases.

All standards are applicable to the research group. The control group was non-metastatic colon cancer patients. In the inclusion criteria (3), patients were diagnosed as colon cancer by pathology. In the exclusion criteria (2), all patients with distant metastasis including live were excluded, and all other criteria were applicable.

\section{Treatment Method}

The RG was treated with radiofrequency ablation: patients were fasted for at least 8 hours before operation and applied the lying posture. The puncture point was marked according to CT and ultrasound influence results, the maximum diameter of the tumor was inserted through cool-tip bundle or single needle after local anesthesia, and then the ablation was performed for $12-15 \mathrm{~min}$. The first radio frequency was maintained for $15 \mathrm{~min}$, and then the single region was repeatedly ablated. The ablation time was determined by the degree of the disease, and the number of repeated ablation in a single region was not more than 3 times. Radiological observation showed that the ablation was ended after the ablation scope was complete.

\section{Detection Method}

One week before and after treatment, $5 \mathrm{~mL}$ elbow venous blood of the participants in the RG was collected at about 8 o'clock in the morning, placed in a vacuum blood collection tube containing EDTA-K2, centrifuged at $1500 \mathrm{Xg}$ and at $4^{\circ} \mathrm{C}$ for $15 \mathrm{~min}$, and the supernatant was placed in a new EP tube at $-75^{\circ} \mathrm{C}$ for later use. The participants in the $\mathrm{CG}$ only needed to collect once according to the above steps. The total RNA 
was extracted according to the specification of PURELINK MIRNA ISOLATION KIT (HuiJia Biotechnology Co., Ltd., Xiamen, China, K157001). The concentration of RNA was determined by SpectroArt 200S ultraviolet-visible spectrophotometer (Anatech Co., Ltd., Beijing, China). Referring to the reverse transcription kit (Biolab Technology Co., Ltd., Beijing, China, ALH266-PTO), RNA was reverse transcribed into cDNA and PCR amplification experiments were carried out. U6 was used as the internal reference, and the primer sequences were all collected from Shanghai Qiantu Biotechnology Co., Ltd. miR-210 was quantitatively detected on a real-time fluorescence quantitative PCR system (Nanjing ZhongkeBio Medical Technology Co., Ltd, Nanjing, China, ZKBIO-003) with reference to miRNA qPCR research kit (Genetimes Technology Inc., Shanghai, China, 110001S). Among them, miR-210 upstream: TAATATAGCCCCTGCCCACC, downstream: TATGC TTGTTCTCGTCTCTGTGTC; U6 upstream: ATTGGA ACGATACAGAGAAGATT, downstream: GGAACGCT TCACGAATTTG. All samples were repeatedly tested for 3 times, and the results were tested by $2^{-\Delta \mathrm{CT}}$.

\section{Follow-Up}

The patients were followed up once every 3 months for 5 years by telephone, interview and pathological inquiry to understand the final outcome after intervention. The total survival (OS) was from the beginning of treatment to the time of death or the deadline of the last follow-up, and the disease-free survival time (DFS) was from the beginning of treatment to the time of death or the deadline of the last follow-up due to disease recurrence or disease progression of the patients.

\section{Statistical Analysis}

Statistical analysis was conducted by SPSS20.0 (EasyBio, Beijing, China), and figures were visualized by Graphpad Prism6 (Graphpad Software, San Diego, USA). Counting data was represented by the number of cases/percentage [ $\mathrm{n}$ $(\%)]$, and chi-square test was applied for comparison between groups. The measurement data were represented by mean $\pm \mathrm{SD}$ and compared by independent sample $t$ test, and the comparison before and after treatment was conducted by paired $t$ test. ROC was applied to test the value of miR-210 in diagnosis, recurrence and prognosis of patients. Kaplan-Meier was applied to test OS and DFS.
Table I Baseline Data of RG and CGs of Patients [n (\%), mean $\pm \mathrm{SD}]$

\begin{tabular}{|c|c|c|c|c|c|}
\hline Factor & $\mathbf{n}$ & $\begin{array}{l}\text { RG } \\
(n=150)\end{array}$ & $\begin{array}{l}\text { CG } \\
(n=130)\end{array}$ & $\chi^{2} / \mathrm{t}$ & $\mathbf{P}$ \\
\hline $\begin{array}{l}\text { Gender } \\
\text { Male } \\
\text { Female }\end{array}$ & $\begin{array}{l}154 \\
126\end{array}$ & $\begin{array}{l}79(52.67) \\
71 \text { (47.33) }\end{array}$ & $\begin{array}{l}75(57.69) \\
55(42.31)\end{array}$ & 0.711 & 0.399 \\
\hline $\begin{array}{l}\text { Age (years) } \\
<60 \\
\geq 60 \\
\text { Average age } \\
\text { (years) }\end{array}$ & $\begin{array}{l}125 \\
155 \\
280\end{array}$ & $\begin{array}{l}66(44.00) \\
84(56.00) \\
62.02 \\
\pm 15.37\end{array}$ & $\begin{array}{l}59(45.38) \\
7 I(54.62) \\
6 I .56 \\
\pm 13.87\end{array}$ & 0.261 & $\begin{array}{l}0.816 \\
0.794\end{array}$ \\
\hline $\begin{array}{l}\text { Drinking } \\
\text { history } \\
\text { No } \\
\text { Yes }\end{array}$ & $\begin{array}{l}154 \\
126\end{array}$ & $\begin{array}{l}76(50.67) \\
74(49.33)\end{array}$ & $\begin{array}{l}78(60.00) \\
52(40.00)\end{array}$ & 0.117 & $2.45 \mathrm{I}$ \\
\hline $\begin{array}{l}\text { Smoking } \\
\text { history } \\
\text { No } \\
\text { Yes }\end{array}$ & $\begin{array}{l}173 \\
107\end{array}$ & $\begin{array}{l}87(58.00) \\
63(42.00)\end{array}$ & $\begin{array}{l}86(66.15) \\
44(33.85)\end{array}$ & 1.961 & 0.161 \\
\hline $\begin{array}{l}\text { TNM phase } \\
\text { I-II } \\
\text { III-IV }\end{array}$ & $\begin{array}{l}121 \\
159\end{array}$ & $\begin{array}{l}68(45.33) \\
82(54.67)\end{array}$ & $\begin{array}{l}53(40.77) \\
77(59.23)\end{array}$ & 0.591 & 0.442 \\
\hline $\begin{array}{l}\text { Invasion depth } \\
\text { TI-T2 } \\
\text { T3-T4 }\end{array}$ & $\begin{array}{l}124 \\
156\end{array}$ & $\begin{array}{l}62(41.33) \\
88(58.67)\end{array}$ & $\begin{array}{l}62(47.69) \\
68(52.31)\end{array}$ & $1.14 \mid$ & 0.285 \\
\hline $\begin{array}{l}\text { Lymph node } \\
\text { metastasis } \\
\text { No } \\
\text { Yes }\end{array}$ & $\begin{array}{l}159 \\
121\end{array}$ & $\begin{array}{l}81(54.00) \\
69(46.00)\end{array}$ & $\begin{array}{l}78(60.00) \\
52(40.00)\end{array}$ & 1.022 & 0.312 \\
\hline $\begin{array}{l}\text { Distant } \\
\text { metastasis } \\
\text { MO } \\
\text { MI }\end{array}$ & $\begin{array}{l}162 \\
118\end{array}$ & $\begin{array}{l}85(56.67) \\
65(43.33)\end{array}$ & $\begin{array}{l}77(59.23) \\
53(40.77)\end{array}$ & 0.188 & 0.665 \\
\hline $\begin{array}{l}\text { Tumor size } \\
(\mathrm{cm}) \\
<5 \\
\geq 5\end{array}$ & $\begin{array}{l}125 \\
155\end{array}$ & $\begin{array}{l}64(42.67) \\
86(57.33)\end{array}$ & $\begin{array}{l}61(46.92) \\
69(53.08)\end{array}$ & $0.5 \mathrm{II}$ & 0.475 \\
\hline $\begin{array}{l}\text { Degree of } \\
\text { pathological } \\
\text { differentiation } \\
\text { Medium and } \\
\text { high } \\
\text { differentiation } \\
\text { Poor } \\
\text { differentiation }\end{array}$ & 183 & $\begin{array}{l}55(36.67) \\
95(63.33)\end{array}$ & $\begin{array}{l}42(32.31) \\
88(67.69)\end{array}$ & 0.584 & 0.445 \\
\hline
\end{tabular}

Abbreviations: RG, research group; CG, control group. 
A

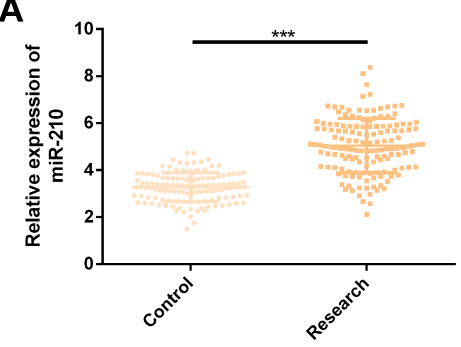

B

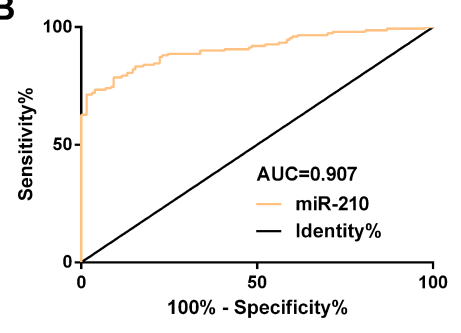

Figure I Expression of miR-210 in serum of colon carcinoma patients with hepatic metastasis. (A) miR-210 was up-regulated in serum of colon carcinoma patients with hepatic metastasis. (B) ROC curve of miR-210 in identifying hepatic metastasis of colon carcinoma.

Note: *** Means compared between the RG and the CGs, $\mathrm{P}<0.001$.

Abbreviations: miR, microRNA; ROC, receiver operating characteristic curve; AUC, area under the curve; RG, research group; CG, control group.

Log rank test was applied to test the difference in survival between groups. Univariate and multivariate Cox regression analysis were applied to analyze the prognostic factors of patients. $\mathrm{P}<0.05$ was considered to be statistically different.

\section{Result}

\section{Baseline Data}

There was no evident difference in gender, age, average age, drinking history, smoking history, TNM stage, invasion depth, lymph node metastasis, distant metastasis, tumor size and pathological differentiation degree between the RG and the CG $(\mathrm{P}>0.05)$. See Table 1.

\section{miR-2 I 0 Up-Regulated in Serum of Patients with Hepatic Metastasis of CC}

In order to explore whether miR-210 has imbalance in hepatic metastasis of colon carcinoma, we detected its serum expression in two groups of patients. The results showed that the miR-210 in the RG was evidently higher than that in the $\mathrm{CG}(\mathrm{P}<0.001)$. We also visualized the ROC curve for distinguishing liver metastases from CC. The data showed that the AUC was as high as 0.907 (95\% CI: $0.872-0.942)$, the sensitivity and specificity were $71.33 \%, 98.46 \%$, respectively, and the optimal cut-off value was 4.47. See Figure 1.

\section{miR-2 10 Was Associated with Pathological Parameters of CC Patients with Hepatic Metastasis}

In order to explore whether serum miR-210 could evaluate the pathological parameters of patients with liver metastases of CC, we analyzed its expression in the pathological parameters of patients. The results showed that miR-210 had no evident correlation with sex, age, TNM stage, invasion depth, and tumor size $(\mathrm{P}>0.05)$, but had evident correlation with lymph node metastasis, distant metastasis and pathological differentiation degree $(\mathrm{P}<0.05)$. See Table 2.

Table 2 Relationship Between miR-210 and Pathological Parameters of CC Patients with Hepatic Metastasis (mean \pm SD)

\begin{tabular}{|c|c|c|c|c|}
\hline Parameter & $\mathbf{n}$ & miR-2 I 0 & $\mathbf{t}$ & $\mathbf{P}$ \\
\hline Gender & & & 1.405 & 0.161 \\
\hline Male & 154 & $5.11 \pm 0.85$ & & \\
\hline Female & 126 & $4.98 \pm 0.66$ & & \\
\hline Age (years) & & & 1.812 & 0.071 \\
\hline$\leq 60$ & 125 & $4.94 \pm 0.78$ & & \\
\hline$>60$ & 155 & $5.13 \pm 0.94$ & & \\
\hline TNM stage & & & 1.189 & 0.236 \\
\hline I-II & 121 & $4.95 \pm 0.87$ & & \\
\hline III-IV & 159 & $5.09 \pm 1.05$ & & \\
\hline Invasion depth & & & 1.870 & 0.063 \\
\hline TI-T2 & 124 & $4.90 \pm 0.90$ & & \\
\hline T3-T4 & 156 & $5.13 \pm 1.11$ & & \\
\hline Lymph node & & & 6.306 & $<0.001$ \\
\hline metastasis & & & & \\
\hline No & 159 & $4.78 \pm 1.02$ & & \\
\hline Yes & 121 & $5.50 \pm 0.84$ & & \\
\hline Distant metastasis & & & 4.461 & $<0.001$ \\
\hline No & 162 & $4.84 \pm 1.15$ & & \\
\hline Yes & 118 & $5.4 I \pm 0.9 I$ & & \\
\hline Tumor size $(\mathrm{cm})$ & & & 1.088 & 0.278 \\
\hline$<5$ & 125 & $5.13 \pm 0.92$ & & \\
\hline$\geq 5$ & 155 & $5.00 \pm 1.05$ & & \\
\hline Degree of & & & 6.326 & $<0.001$ \\
\hline pathological & & & & \\
\hline differentiation & & & & \\
\hline Medium and high & 97 & $4.78 \pm 1.02$ & & \\
\hline differentiation & & & & \\
\hline Poor differentiation & 183 & $5.50 \pm 0.84$ & & \\
\hline
\end{tabular}

Abbreviations: miR, microRNA; CC, colon carcinoma; TNM, tumor node metastasis. 


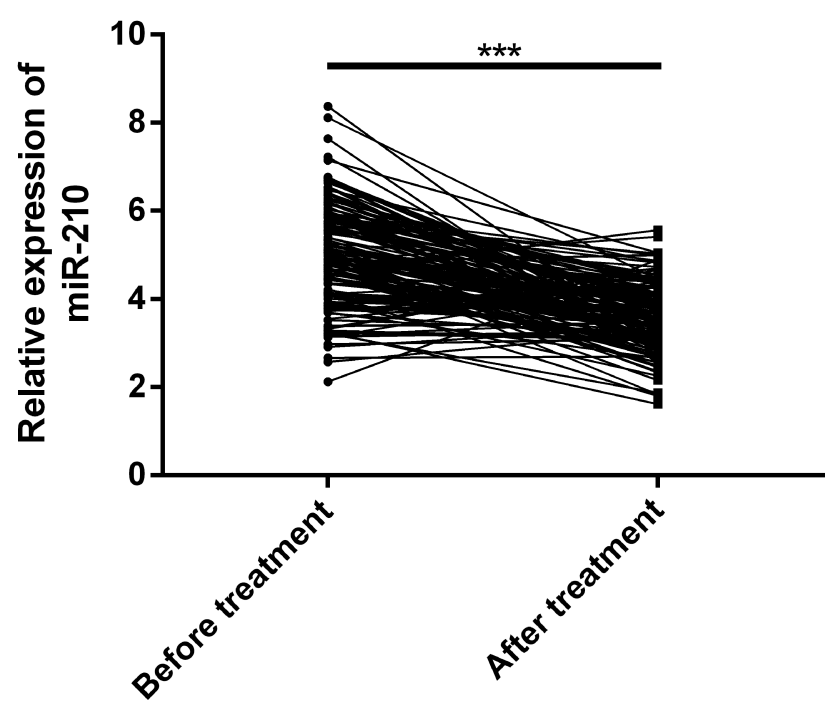

Figure 2 Expression of miR-210 in colon carcinoma patients with hepatic metastasis before and after treatment. miR-210 was evidently down-regulated after treatment for liver metastases of colon carcinoma.

Note: *** Means compared between the RG and the CGs, $\mathrm{P}<0.00 \mathrm{I}$.

Abbreviations: miR, microRNA; RG, research group; CG, control group.

\section{miR-2I 0 Down-Regulated Evidently After Treatment for Hepatic Metastasis of CC}

In order to explore whether miR-210 responded to the therapeutic effect of radiofrequency ablation, we analyzed its expression before and after treatment. The results revealed that miR-210 in the RG and the CG after intervention was evidently lower than that before intervention $(\mathrm{P}<0.001)$. See Figure 2.

\section{miR-2 10 Up-Regulated Evidently in Patients with Hepatic Metastasis and Recurrence of $\mathrm{CC}$ and Even Patients with Poor Prognosis}

Further exploring the recurrence and prognostic value of miR-210 in hepatic metastasis of colon carcinoma revealed that miR-210 had higher serum expression in recurrent patients and patients with poor prognosis $(\mathrm{P}<0.001)$. By visualizing the ROC curve for predicting recurrence, we found that the AUC reached $0.858(95 \%$ CI: $0.807-0.894)$, the sensitivity and specificity were $72.41 \%$ and $87.30 \%$, respectively, and the best cut-off value was 4.96. However, AUC for predicting poor prognosis was 0.843 (95\% CI: $0.780-0.907)$, the sensitivity and specificity were $77.33 \%$ and $78.67 \%$, respectively, and the best cut-off value was 4.58. See Figure 3 and Table 3.

\section{High-Level miR-210 Was Evidently Associated with Lower OS and DFS in 5 Years in Patients with Liver Metastases from CC}

In order to understand the relationship between miR-210 and the survival of $\mathrm{CC}$ patients with hepatic metastasis, the
A

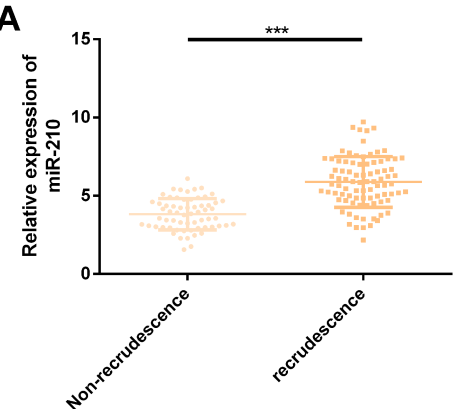

C

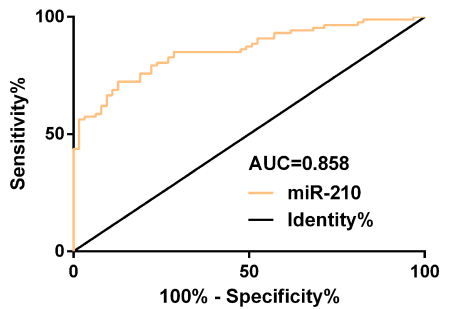

B

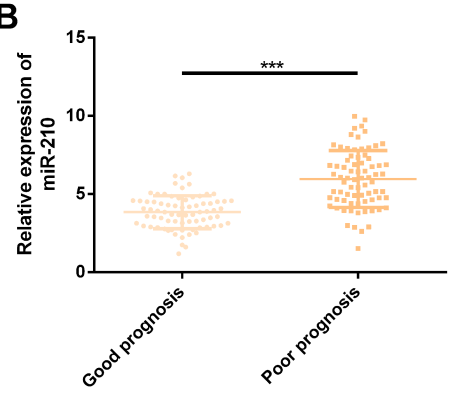

D

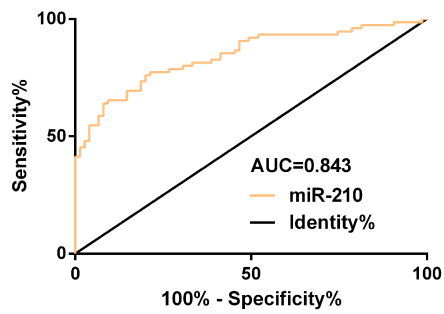

Figure 3 Expression and predictive value of miR-2I0 in hepatic metastasis, recurrence and poor prognosis of colon carcinoma. (A) miR-2I0 was evidently up-regulated in patients with hepatic metastasis and recurrence of colon carcinoma. (B) miR-210 was evidently up-regulated in patients with poor prognosis. (C) ROC curve of miR-2I0 predicting hepatic metastasis and recurrence of colon carcinoma. (D) ROC curve of miR-2I 0 predicting poor prognosis of hepatic metastasis from colon carcinoma. Note: ***Means compared between the RG and the CGs, $P<0.001$.

Abbreviations: miR, microRNA; ROC, receiver operating characteristic curve; AUC, area under the curve; RG, research group; CG, control group. 
Table 3 ROC Parameters of miR-2 10 for Predicting Recurrence or Poor Prognosis of CC Patients with Hepatic Metastasis

\begin{tabular}{|l|l|l|l|l|l|l|}
\hline Objective & AUC & $\mathbf{9 5 \%} \mathbf{~ C l}$ & Standard Error & Cut-off Value & Sensitivity (\%) & Specificity (\%) \\
\hline Recurrence prediction & 0.858 & $0.800-0.916$ & 0.030 & 4.96 & 72.41 & 87.30 \\
Prognostic prediction & 0.843 & $0.780-0.907$ & 0.032 & 4.58 & 77.33 & 78.67 \\
\hline
\end{tabular}

Abbreviations: ROC, receiver operating characteristic curve; miR, microRNA; CC, colon carcinoma; AUC, area under the curve.

5-year OS and DFS curves were visualized. In this study, the 5-year follow-up was successfully completed, with OS and DFS of $50.00 \%(75 / 150)$ and $40.00 \%(60 / 150)$ in 5 years. In our survival curve, the median expression of miR-210 (4.57) was taken as the critical point. The results showed that highlevel miR-210 was evidently correlated with lower OS and DFS in 5 years $(\mathrm{P}<0.001)$. We also analyzed the prognostic factors of hepatic metastasis of $\mathrm{CC}$ by $\mathrm{Cox}$ analysis. The results showed that TNM stage $(\mathrm{P}=0.019)$, lymph node metastasis $(\mathrm{P}=0.023)$, distant metastasis $(\mathrm{P}=0.015)$ and miR-210 $(\mathrm{P}=0.009)$ were independent prognostic factors of poor prognosis of hepatic metastasis of CC. High stage TNM, lymph node metastasis, distant metastasis and high miR-210 (>4.57) increased the risk of poor prognosis of hepatic metastasis of CC. See Figure 4 and Table 4.

\section{Discussion}

Hepatic metastasis of $\mathrm{CC}$ is a dangerous state of $\mathrm{CC}$, which still has high recurrence rate and low survival rate even after surgical resection. ${ }^{18,19}$ Radiofrequency ablation, as an effective treatment for colon carcinoma patients with hepatic metastasis, can even replace hepatectomy in some cases to exert therapeutic effect. ${ }^{20} \mathrm{miR}-210$, as a biological indicator of colon carcinoma, has shown better diagnostic value, ${ }^{21}$ but there is still little research on recurrence and prognosis prediction after radiofrequency ablation. In this study, we will carry out correlation analysis based on miR210 , which is of great significance for optimizing the treatment strategy for hepatic metastasis of colon carcinoma.
Previous studies have shown many evidences, which proved that miR-210 was highly correlated with colon carcinoma. For example, in the research of Ullmann et al, ${ }^{22} \mathrm{miR}$ 210 could inhibit the self-renewal ability of tumor initiation cells around ISCU by targeting in hypoxic colon carcinoma cells. Another report of Bigagli et $\mathrm{al}^{23}$ indicated that miR210 , as an exosome, can affect the adhesion of colon carcinoma metastatic cells and has an important regulatory role on the metastatic behavior of tumor cells. In our research, miR210 was evidently high in patients with hepatic metastases of $\mathrm{CC}$, indicating that miR-210 may be involved in the pathological process of hepatic metastases of CC. In the report of Wang et al, ${ }^{13}$ miR-210 was also up-regulated in the serum of colon carcinoma patients, which was similar to our research results. In addition, miR-210 also had abnormal upregulation in other malignant tumors, such as breast carcinoma, glioma, and venous metastatic hepatocellular carcinoma. $^{24-26}$ Further analyzing the diagnostic effect of miR-210 in hepatic metastasis of colon carcinoma, we found that the AUC for differentiating hepatic metastasis of colon carcinoma from non-metastatic colon carcinoma was 0.907 , and the sensitivity and specificity were $71.33 \%$ and $98.46 \%$, respectively, suggesting that miR-210, as a serum index, had higher diagnostic value and specificity for identifying hepatic metastasis of colon carcinoma. We also explored the correlation of miR-210 with pathological parameters of patients. The results showed that miR-210 had a close correlation with lymph node metastasis, distant metastasis and degree of pathological differentiation.
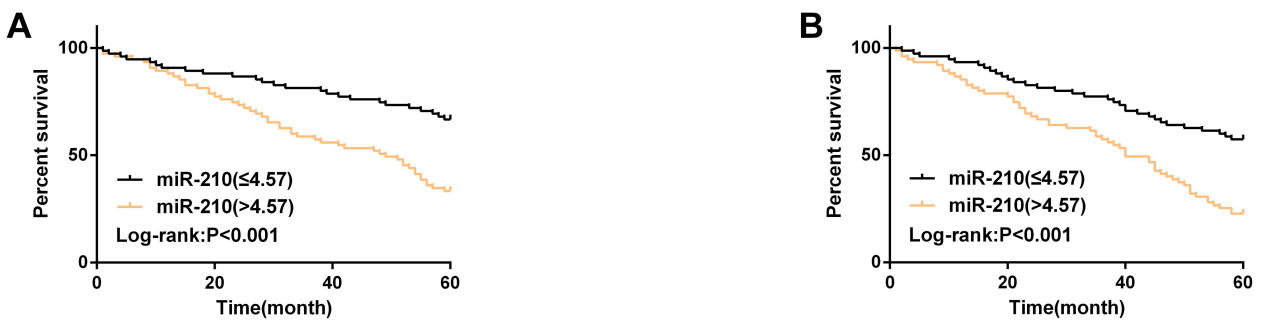

Figure 4 The correlation of the 5-year OS and DFS of colon carcinoma patients with hepatic metastasis with miR-210. (A) High-level miR-2I0 was associated with lower 5 -year OS in patients with liver metastases of colon carcinoma. (B) High-level miR-210 was associated with lower 5-year DFS in patients with liver metastases of colon carcinoma.

Abbreviations: miR, microRNA; OS, overall survival; DFS, disease-free survival. 
Table 4 Cox Analysis on Prognosis of Patients with Hepatic Metastasis from CC

\begin{tabular}{|c|c|c|c|c|}
\hline \multirow[t]{2}{*}{ Parameter } & \multicolumn{2}{|l|}{ Single Factor } & \multicolumn{2}{|c|}{ Multiple Factors } \\
\hline & $\begin{array}{l}\text { HR }(95 \% \\
\mathrm{Cl})\end{array}$ & $\mathbf{P}$ & $\begin{array}{l}\text { HR }(95 \% \\
\mathrm{Cl})\end{array}$ & $\mathbf{P}$ \\
\hline Gender & $\begin{array}{l}\text { I.209 } \\
(0.789-2.164)\end{array}$ & 0.220 & & \\
\hline Age & $\begin{array}{l}\text { I. } 108 \\
(0.902-I .544)\end{array}$ & 0.103 & & \\
\hline TNM stage & $\begin{array}{l}3.343 \\
(2.009-2.163)\end{array}$ & 0.017 & $\begin{array}{l}1.963 \\
(1.226-3.078)\end{array}$ & 0.019 \\
\hline Invasion depth & $\begin{array}{l}0.001 \\
(2.321-4.125)\end{array}$ & 0.001 & $\begin{array}{l}0.828 \\
(0.374-1.000)\end{array}$ & 0.295 \\
\hline $\begin{array}{l}\text { Lymph node } \\
\text { metastasis }\end{array}$ & $\begin{array}{l}1.698 \\
(1.218-2.649)\end{array}$ & 0.025 & $\begin{array}{l}1.733 \\
(1.192-3.622)\end{array}$ & 0.023 \\
\hline $\begin{array}{l}\text { Distant } \\
\text { metastasis }\end{array}$ & $\begin{array}{l}3.877 \\
(1.491-3.462)\end{array}$ & $<0.001$ & $\begin{array}{l}2.37 \mid \\
(1.560-4.289)\end{array}$ & 0.015 \\
\hline Tumor size & $\begin{array}{l}1.735 \\
(1.006-2.996)\end{array}$ & 0.048 & $\begin{array}{l}1.064 \\
(0.58 I-1.927)\end{array}$ & 0.831 \\
\hline $\begin{array}{l}\text { Degree of } \\
\text { pathological } \\
\text { differentiation }\end{array}$ & $\begin{array}{l}2.220 \\
(1.202-2.507)\end{array}$ & 0.009 & $\begin{array}{l}1.475 \\
(0.898-2.416)\end{array}$ & 0.124 \\
\hline miR-2I 0 & $\begin{array}{l}2.879 \\
(1.340-2.7 \mid 4)\end{array}$ & 0.001 & $\begin{array}{l}3.006 \\
(2.457-6.008)\end{array}$ & 0.009 \\
\hline
\end{tabular}

Abbreviations: CC, colon carcinoma; TNM, tumor node metastasis; miR, microRNA.

Higher level miR-210 had a correlation with lymph node metastasis, distant metastasis and degree of low differentiation, indicating that miR-210 was helpful to evaluate the above pathological parameters of patients.

miR-210 was also actively responsive to the treatment of radiofrequency ablation in patients with hepatic metastases of $\mathrm{CC}$, and its expression was evidently downregulated after treatment. In addition, the recurrence rate of our 150 patients was $58.0 \%$, which was similar to $60.6 \%$ of Min et al. ${ }^{27}$ In the follow-up results, the 5-year OS and DFS were $50.0 \%$ and $40.0 \%$, respectively, which were similar to the results of Spelt et $\mathrm{al}^{28}$ (the 5 -year OS: $52.0 \%$, the 5-year DFS: $37.0 \%$ ). We also evaluated its predictive value in predicting recurrence and poor prognosis of patients after radiofrequency ablation. The results showed that its AUC for predicting the recurrence was 0.858 , while that for predicting the prognosis was 0.843 , suggesting that miR-210 had multiple predictive efficacy, which not only can be used as a potential predictive indicator for recurrence of $\mathrm{CC}$ patients with hepatic metastasis, but also has gratifying value for prognosis prediction. In the report by Chen et al, ${ }^{29}$ up-regulation of miR-210 was helpful to identify pathological conditions of colon carcinoma, such as local recurrence, distant metastasis and poor prognosis, which were similar to our results. In the research of Zhang et al, ${ }^{30}$ high miR-210-3p was also pointed out to increase the recurrence risk of renal cell carcinoma (RCC), which can be used as a recurrence prediction index of RCC. In addition, Tang et $\mathrm{al}^{31}$ reported that the high miR-210 in acute myeloid leukemia was significantly related to the lower recurrence-free survival rate of patients, suggesting that miR-210 also had certain recurrence prediction potential in this disease. All the above results confirmed that miR-210 had certain recurrence prediction value in different disease backgrounds. Subsequently, we also made an analysis of survival and prognosis factors, indicating that patients with high-level miR-210 (>4.57) had lower OS and DFS for 5 years, which was evidently related to poor prognosis. Cox analysis showed that TNM stage, lymph node metastasis, distant metastasis and miR-210 were independent prognostic factors for poor prognosis of CC patients with hepatic metastasis. Patients with high stage TNM, lymph node metastasis, distant metastasis and high miR-210 ( $>4.57)$ had an increased risk of poor prognosis.

Although our research confirmed that miR-210, as a serological indicator, had potential high value for predicting the recurrence and prognosis of hepatic metastasis of CC. However, there are still some shortcomings in our research. First, we can supplement the predictive value analysis of miR-210 for the curative effect of colon carcinoma hepatic metastasis. Secondly, we can also supplement the analysis of risk factors that affect the curative effect of hepatic metastasis or recurrence of colon carcinoma. In addition, we can also focus on the molecular mechanism of miR-210 in hepatic metastasis of colon carcinoma and conduct basic research to explore potential therapeutic methods. We will gradually improve the research based on the above improvement points in the future.

\section{Conclusion}

To sum up, we proposed for the first time that miR-210 is a serological biomarker for predicting recurrence and prognosis of colon carcinoma patients with liver metastases after radiofrequency ablation, providing new clues for recurrence and prognosis prediction of patients. 


\section{Acknowledgments}

This study was financially supported up The Application of Assessing the Ablation Efficacy for colorectal cancer liver metastasis and predicting the local recurrence in early stage by using multimodal MR Imaging and Scientific research Subject of Sichuan Health Committee - application project (17PJ376).

\section{Disclosure}

The authors report no conflicts of interest in this work.

\section{References}

1. Muto Y, Furihata T, Kaneko M, et al. Different response profiles of gastrointestinal cancer cells to an L-type amino acid transporter inhibitor, JPH203. Anticancer Res. 2019;39(1):159-165. doi:10.21873/anticanres. 13092

2. Principe DR, DeCant B, Staudacher J, et al. Loss of TGFbeta signaling promotes colon cancer progression and tumor-associated inflammation. Oncotarget. 2017;8(3):3826-3839. doi:10.18632/oncotarget.9830

3. Wang L, Wei Z, Wu K, et al. Long noncoding RNA B3GALT5-AS1 suppresses colon cancer liver metastasis via repressing microRNA-203. Aging (Albany NY). 2018;10(12):3662-3682. doi:10.18632/aging.101628

4. Fujisawa S, Romin Y, Barlas A, et al. Evaluation of YO-PRO-1 as an early marker of apoptosis following radiofrequency ablation of colon cancer liver metastases. Cytotechnology. 2014;66(2):259-273. doi:10.1007/s10616-013-9565-3

5. Chua JME, Lam YMP, Tan BS, et al. Single-centre retrospective review of risk factors for local tumour progression and complications in radiofrequency ablation of 555 hepatic lesions. Singapore Med J. 2019;60(4):188-192. doi:10.11622/smedj.2019036

6. Hu M, Zhou X, Wang Y, Guan K, Huang L. Relaxin-FOLFOX-IL-12 triple combination therapy engages memory response and achieves long-term survival in colorectal cancer liver metastasis. $J$ Control Release. 2020;319:213-221. doi:10.1016/j.jconrel.2019.12.053

7. Alzahrani N, Ung L, Valle SJ, Liauw W, Morris DL. Synchronous liver resection with cytoreductive surgery for the treatment of liver and peritoneal metastases from colon cancer: results from an Australian centre. ANZ J Surg. 2017;87(11):E167-E172. doi:10.1111/ans.13231

8. Ge Y, Zhang L, Nikolova M, Reva B, Fuchs E. Strand-specific in vivo screen of cancer-associated miRNAs unveils a role for miR21(*) in SCC progression. Nat Cell Biol. 2016;18(1):111-121. doi:10.1038/ncb3275

9. Fantini S, Salsi V, Reggiani L, Maiorana A, Zappavigna V. The miR-196b miRNA inhibits the GATA6 intestinal transcription factor and is upregulated in colon cancer patients. Oncotarget. 2017;8 (3):4747-4759. doi:10.18632/oncotarget. 13580

10. Zuberi M, Khan I, Mir R, Gandhi G, Ray PC, Saxena A. Utility of serum miR-125b as a diagnostic and prognostic indicator and its alliance with a panel of tumor suppressor genes in epithelial ovarian cancer. PLoS One. 2016;11(4):e0153902. doi:10.1371/journal. pone. 0153902

11. Liu C, Eng C, Shen J, et al. Serum exosomal miR-4772-3p is a predictor of tumor recurrence in stage II and III colon cancer. Oncotarget. 2016;7(46):76250-76260. doi:10.18632/oncotarget.12841

12. Shi W, Lu Y, Gong R, Sun JJ, Liu G. Serum miR-629 is a novel molecular marker for diagnosis and the prognosis of pancreatic cancer. Eur Rev Med Pharmacol Sci. 2018;22(16):5187-5193. doi:10.26355/eurrev_201808_15715
13. Wang W, Qu A, Liu W, et al. Circulating miR-210 as a diagnostic and prognostic biomarker for colorectal cancer. Eur J Cancer Care. 2017;26(4):e12448. doi:10.1111/ecc.12448

14. Pranzini E, Leo A, Rapizzi E, et al. miR-210-3p mediates metabolic adaptation and sustains DNA damage repair of resistant colon cancer cells to treatment with 5-fluorouracil. Mol Carcinog. 2019;58 (12):2181-2192. doi:10.1002/mc.23107

15. Sun Y, Xing X, Liu Q, et al. Hypoxia-induced autophagy reduces radiosensitivity by the HIF-1alpha/miR-210/Bcl-2 pathway in colon cancer cells. Int $J$ Oncol. 2015;46(2):750-756. doi:10.3892/ ijo.2014.2745

16. Pizzini S, Bisognin A, Mandruzzato S, et al. Impact of microRNAs on regulatory networks and pathways in human colorectal carcinogenesis and development of metastasis. BMC Genomics. 2013;14:589. doi:10.1186/1471-2164-14-589

17. Van Blarigan EL, Fuchs CS, Niedzwiecki D, et al. Marine omega-3 polyunsaturated fatty acid and fish intake after colon cancer diagnosis and survival: CALGB 89803 (Alliance). Cancer Epidemiol Biomarkers Prev. 2018;27(4):438-445. doi:10.1158/1055-9965.EPI17-0689

18. Kim WJ, Lim TW, Kang SH, et al. Development and validation of novel scoring system for the prediction of disease recurrence following resection of colorectal liver metastasis. Asian J Surg. 2020;43 (2):438-446. doi:10.1016/j.asjsur.2019.06.001

19. Yano S, Takehara K, Miwa S, et al. Improved resection and outcome of colon-cancer liver metastasis with fluorescence-guided surgery using in situ GFP labeling with a telomerase-dependent adenovirus in an orthotopic mouse model. PLoS One. 2016;11(2):e0148760. doi:10.1371/journal.pone. 0148760

20. Lee BC, Lee HG, Park IJ, et al. The role of radiofrequency ablation for treatment of metachronous isolated hepatic metastasis from colorectal cancer. Medicine (Baltimore). 2016;95(39):e4999. doi:10.1097/ MD.0000000000004999

21. Sabry D, El-Deek SEM, Maher M, et al. Role of miRNA-210, miRNA-21 and miRNA-126 as diagnostic biomarkers in colorectal carcinoma: impact of HIF-1alpha-VEGF signaling pathway. Mol Cell Biochem. 2019;454(1-2):177-189. doi:10.1007/s11010-018-3462-1

22. Ullmann P, Qureshi-Baig K, Rodriguez F, et al. Hypoxia-responsive miR-210 promotes self-renewal capacity of colon tumor-initiating cells by repressing ISCU and by inducing lactate production. Oncotarget. 2016;7(40):65454-65470. doi:10.18632/oncotarget.1 1772

23. Bigagli E, Luceri C, Guasti D, Cinci L. Exosomes secreted from human colon cancer cells influence the adhesion of neighboring metastatic cells: role of microRNA-210. Cancer Biol Ther. 2016;17 (10):1062-1069. doi:10.1080/15384047.2016.1219815

24. Tang T, Yang Z, Zhu Q, et al. Up-regulation of miR-210 induced by a hypoxic microenvironment promotes breast cancer stem cells metastasis, proliferation, and self-renewal by targeting E-cadherin. FASEB J. 2018;32(12):6965-6981.

25. Shang C, Hong Y, Guo Y, Liu YH, Xue YX. MiR-210 up-regulation inhibits proliferation and induces apoptosis in glioma cells by targeting SIN3A. Med Sci Monit. 2014;20:2571-2577. doi:10.12659/MSM.892994

26. Ji J, Rong Y, Luo CL, et al. Up-regulation of hsa-miR-210 promotes venous metastasis and predicts poor prognosis in hepatocellular carcinoma. Front Oncol. 2018;8:569. doi:10.3389/fonc.2018.00569

27. Min BS, Kim NK, Jeong HC, Chung HC. High levels of serum VEGF and TIMP-1 are correlated with colon cancer liver metastasis and intrahepatic recurrence after liver resection. Oncol Lett. 2012;4 (1):123-130. doi:10.3892/ol.2012.691

28. Spelt L, Sasor A, Ansari D, Andersson R. Pattern of tumour growth of the primary colon cancer predicts long-term outcome after resection of liver metastases. Scand $J$ Gastroenterol. 2016;51 (10):1233-1238. doi:10.1080/00365521.2016.1190400 
29. Chen J, Wang W, Zhang Y, Chen Y, Hu T. Predicting distant metastasis and chemoresistance using plasma miRNAs. Med Oncol. 2014;31(1):799. doi:10.1007/s12032-013-0799-x

30. Zhang J, Ye Y, Chang DW, et al. Global and targeted miRNA expression profiling in clear cell renal cell carcinoma tissues potentially links miR-155-5p and miR-210-3p to both tumorigenesis and recurrence. Am J Pathol. 2018;188(11):2487-2496. doi:10.1016/j. ajpath.2018.07.026
31. Tang X, Chen L, Yan X, Li Y, Xiong Y, Zhou X. Overexpression of miR-210 is associated with poor prognosis of acute myeloid leukemia. Med Sci Monit. 2015;21:3427-3433. doi:10.12659/ MSM.894812

\section{Publish your work in this journal}

Cancer Management and Research is an international, peer-reviewed open access journal focusing on cancer research and the optimal use of preventative and integrated treatment interventions to achieve improved outcomes, enhanced survival and quality of life for the cancer patient.
The manuscript management system is completely online and includes a very quick and fair peer-review system, which is all easy to use. Visit http://www.dovepress.com/testimonials.php to read real quotes from published authors. 